OPEN

SUBJECT AREAS:

ECOLOGY

MICROBIAL ECOLOGY

ATMOSPHERIC SCIENCE

Received

14 April 2014

Accepted

3 September 2014

Published

22 October 2014

Correspondence and requests for materials should be addressed to J.P. (josep.penuelas@ vab.cat)

\title{
Removal of floral microbiota reduces
} floral terpene emissions

\author{
Josep Peñuelas 1,2, Gerard Farré-Armengol 1,2, Joan Llusia 1,2, Albert Gargallo-Garriga ${ }^{1,2,3}$, Laura Rico 1,2, \\ Jordi Sardans ${ }^{1,2}$, Jaume Terradas ${ }^{2,4}$ \& lolanda Filella ${ }^{1,2}$
}

${ }^{1}$ CSIC, Global Ecology Unit CREAF-CSIC-UAB, Cerdanyola del Vallès, 08193 Barcelona, Catalonia, Spain, ${ }^{2}$ CREAF, Cerdanyola del Vallès, 08193 Barcelona, Catalonia, Spain, ${ }^{3}$ Servei de Ressonància Magnètica, Faculty of Sciences and Biosciences, Universitat Autònoma de Barcelona, Bellaterra, 08193 Barcelona, Catalonia, Spain, ${ }^{4}$ Departament de Biologia Vegetal, Animal i Ecologia, Universitat Autònoma de Barcelona, Cerdanyola del Vallès, 08913 Barcelona, Catalonia, Spain.

The emission of floral terpenes plays a key role in pollination in many plant species. We hypothesized that the floral phyllospheric microbiota could significantly influence these floral terpene emissions because microorganisms also produce and emit terpenes. We tested this hypothesis by analyzing the effect of removing the microbiota from flowers. We fumigated Sambucus nigra L. plants, including their flowers, with a combination of three broad-spectrum antibiotics and measured the floral emissions and tissular concentrations in both antibiotic-fumigated and non-fumigated plants. Floral terpene emissions decreased by ca. two thirds after fumigation. The concentration of terpenes in floral tissues did not decrease, and floral respiration rates did not change, indicating an absence of damage to the floral tissues. The suppression of the phyllospheric microbial communities also changed the composition and proportion of terpenes in the volatile blend. One week after fumigation, the flowers were not emitting $\beta$-ocimene, linalool, epoxylinalool, and linalool oxide. These results show a key role of the floral phyllospheric microbiota in the quantity and quality of floral terpene emissions and therefore a possible key role in pollination.

P roficient performance in plants is strongly associated with distinct microbial communities that live in and on the organs. These communities are especially important in roots ${ }^{1,2}$. The microbiotas of the phyllosphere (in above-ground plant tissues and on above-ground plant surfaces) are abundant and are assumed to play critical roles in protecting plants from diseases and in promoting growth by various mechanisms. They may also offer indirect protection against pathogens ${ }^{3-5}$ and contribute to plant communication with different types and quantities of biogenic volatile organic compounds (BVOCs) $)^{3,4}$. Microbiotas, however, have generally not been well characterized, and little is known about their actual physiological and ecological roles ${ }^{3,4,6-8}$. The composition and physiological and ecological roles are much less well known for the microbiotas in and on flowers than for those in and on leaves. Microorganisms produce and emit many BVOCs including several terpenes ${ }^{9}$, so we hypothesized that floral phyllospheric microbiotas could significantly contribute to the emission of BVOCs, including terpenes, that play a key role in attracting pollinators ${ }^{10}$. Here we tested this hypothesis by studying the floral emissions of Sambucus nigra L. flowers before and after removal of their floral microbiota with a combination of three broad-spectrum antibiotics: streptomycin, oxytetracycline, and chloramphenicol.

\section{Results}

Reduced diversity and rates of emission of floral terpenes. The total floral emissions of terpenes decreased after antibiotic fumigation by nearly two thirds (Fig. 1a). The flowers of $S$. nigra emitted a terpene mixture dominated by linalool, with lower emission rates of $(\mathrm{Z})$ - $\beta$-ocimene and two oxygenated terpenes derived from linalool, epoxylinalool and linalool oxide (Fig. 2a). The composition of the emissions significantly changed after fumigation (pseudo- $F=6.66, P=0.05$ ) (Fig. $2 \mathrm{a}$ ). The percentage of trans- $\beta$-ocimene decreased from 7 to $0.4 \%(F=10.05, P<0.05)$ by day 2 . By day 8 , trans- $\beta$-ocimene, linalool, epoxylinalool, and linalool oxide were not emitted by the fumigated flowers (Fig. 2a).

Unaltered floral terpene contents. In contrast with terpene emissions, the terpene concentrations of floral extracts did not change in the fumigated plants (Fig. 1b). Floral respiration rates were also not altered by fumigation (Fig. 1c), indicating an absence of plant damage.

Even though the emission rates of floral terpenes were high, ranging between 50 and $250 \mu \mathrm{g} \mathrm{gDW}^{-1} \mathrm{~h}^{-1}$ (Fig. 1a), the terpene concentrations of floral extracts ranged from 0.5 to $2.5 \mu \mathrm{gDW}^{-1}$ (Fig. 1b), indicating 


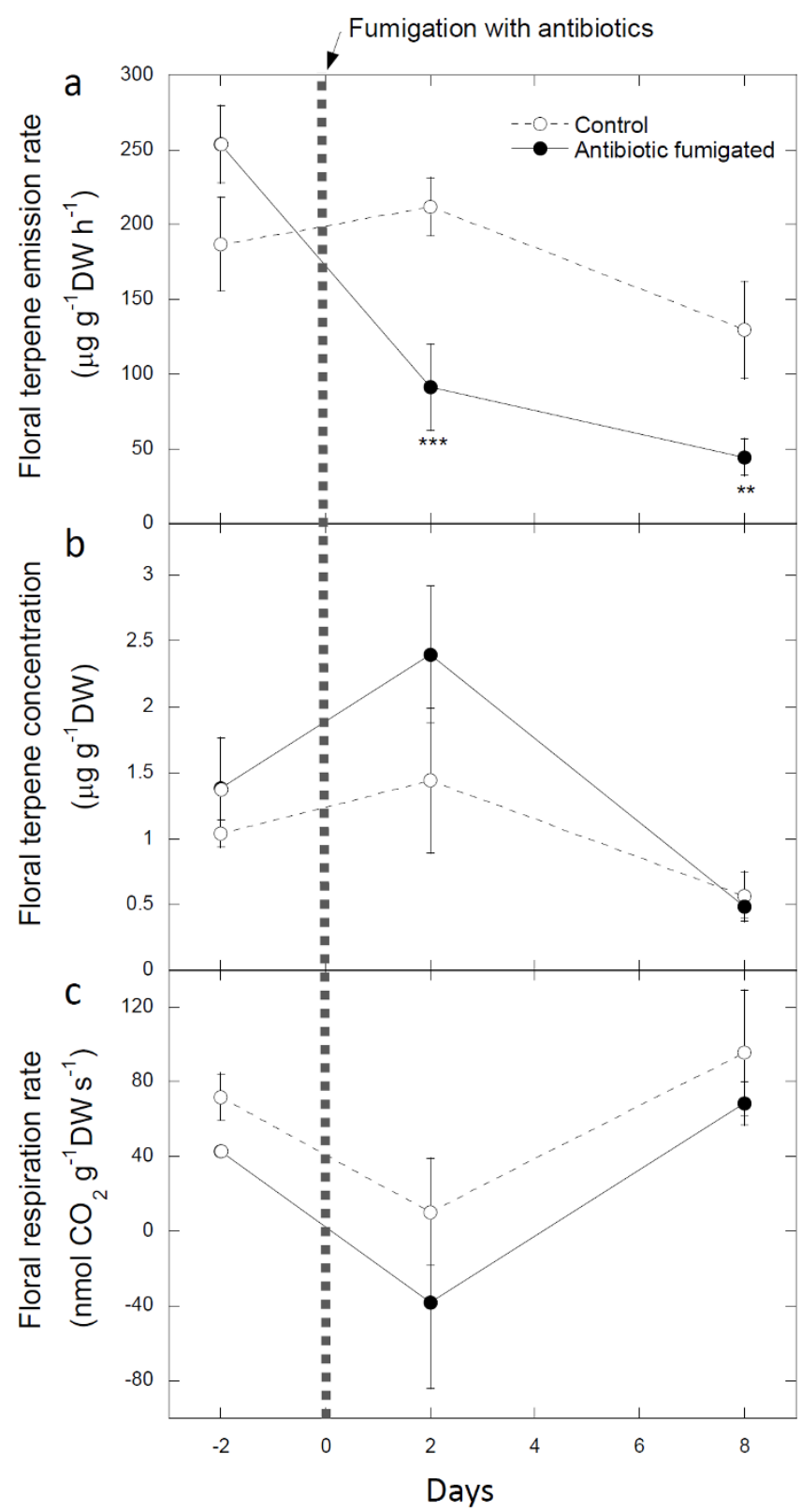

Figure $1 \mid$ Effects of antibiotic fumigation on floral total terpene emissions, total terpene concentrations in floral tissues, and respiration. Time course of floral terpene emission rates (a), floral terpene concentrations (b), and respiration rates (c) of control and antibioticfumigated Sambucus nigra plants. The antibiotics were applied to treated plants on day 0 . The error bars are $\pm \operatorname{SE}(\mathrm{n}=9)$. $* *$ and $* * *$ indicate significant differences between control and antibiotic-fumigated flowers (ANOVA) at $P<0.01$ and $P<0.001$, respectively.

an absence of storage. The extracts were mainly dominated by epoxylinalool (Fig. 2b). Linalool and linalool oxide were also present, although in low amounts, two days before and after fumigation but were not detected on day 8 (Fig. 2b). The compositions of the terpene contents were not significantly different between fumigated and control flowers (Fig. 2b).

\section{Discussion}

The reductions in the rate and diversity of floral terpene emissions in antibiotic-fumigated flowers were not due to a decrease in floral terpene contents. The functioning of the floral tissues did not appear to be altered, as indicated by the unaltered floral respiration rates.
The decrease in emissions was thus likely due to the effect of the antibiotics on the floral phyllospheric microbiota. Bacteria and fungi emit volatile organic compounds from de novo biosynthesis ${ }^{11-13}$ and biotransformation $^{14-16}$, including linalool and other terpenes ${ }^{9,12,16,17}$. Terpene biosynthesis is well known in microbial metabolism, even though only a few bacterial and fungal genes encoding terpene synthases have yet been reported, likely due to the low aminoacid-sequence identities with homologous enzymes in eukaryotes ${ }^{9}$. $\beta$-ocimene and linalool are emitted by yeasts from the genera Debaryomyces, Kluyveromyces, and Pichia ${ }^{14}$, which are commonly found in the nectar of flowers ${ }^{18}$.

The emitted bouquet of $S$. nigra was dominated by linalool $(3,7-$ dimethyl-1,6-octadien-3-ol), an acyclic monoterpene with a sweet, pleasant fragrance common in floral scents ${ }^{19}$. The dominant volatile in the floral extract, however, was epoxylinalool. De-epoxidation to linalool is favored at moderately low $\mathrm{pH}^{20}$, so the frequent presence of phyllospheric microorganisms producing extracellular acidic compounds ${ }^{21,22}$, along with the likely action of microbial epoxide hydrolases $^{23}$, may have favored the emission of linalool.

Other possible effects of the antibiotic treatment, however, cannot be discarded. For example, the presence of certain phyllospheric microbes can induce an emission of defensive terpenes from flowers to control microbial communities ${ }^{5}$. We could thus hypothesize that the removal of phyllospheric microbiotas could have temporarily released the plants from the need to maintain this defensive response, thus reducing the emissions. Direct interference of antibiotics with plant terpene synthesis, their reactions with terpenes, or the release of hydroxyl radicals from dying bacteria by bactericidal antibiotics cannot be fully discarded either.

Flowering plants use diverse, multifunctional biosynthetic pathways to produce a broad spectrum of BVOCs that collectively confer characteristic fragrances to flowers ${ }^{24}$. The results of this study highlight the mostly neglected role of phyllospheric microbiota in these emissions. The attractiveness of floral emissions to a wide range of pollinators, herbivores, and parasitoids and thus the key role emissions play in reproduction and defense may ultimately be due to the direct or indirect action of floral phyllospheric microbiota.

\section{Methods}

Plant material and experimental setup. We used twenty flowering four-year-old potted S. nigra plants grown in a nursery (Tres Turons S.C.P., Castellar del Vallès, Catalonia, Spain) outdoors under ambient Mediterranean conditions. They were grown in $15-\mathrm{L}$ pots with a substrate of peat and sand $(2: 1)$ and received regular irrigation, ensuring that the substrate was held at field capacity throughout the experiment. Ten plants were fumigated with antibiotics. The plants were fumigatedwith $1600 \mathrm{ppm}$ streptomycin, $400 \mathrm{ppm}$ oxytetracycline, and $200 \mathrm{ppm}$ chloramphenicol in $50 \mathrm{ml}$ of $\mathrm{H}_{2} \mathrm{O}$ with $1 \%$ glycerol to ensure the elimination of floral phyllospheric microbiota. These antibiotics are used in agriculture mainly in prophylactic treatments ${ }^{25}$. The other ten plants served as controls and were fumigated with $50 \mathrm{ml} \mathrm{H}_{2} \mathrm{O}$ with $1 \%$ glycerol but without antibiotics. The terpenes in both floral emissions and contents of the control and fumigated plants were measured at day -2 (pre-treatment, two days before fumigation) and at days 2 and 8 (post-treatment) with a dynamic headspace technique.

Measurements of $\mathrm{CO}_{2}$ and BVOC exchange. Floral $\mathrm{CO}_{2}$ and $\mathrm{H}_{2} \mathrm{O}$ exchanges were measured with the LCpro+ Photosynthesis System (ADC BioScientific Ltd., Herts, England $)$ at standard conditions of temperature $\left(30^{\circ} \mathrm{C}\right)$ and light $(\mathrm{PAR}=1000 \mu \mathrm{mol}$ $\left.\mathrm{m}^{-2} \mathrm{~s}^{-1}\right)$. Several flowers from one inflorescence were enclosed in the chamber $\left(175 \mathrm{~cm}^{3}\right)$ without detaching the flowers from the plant. In order to determine and quantify BVOC exchange, flow meters were used to monitor the air entering and exiting the floral chamber and system blanks were sampled previous and after each sampling. The air exiting the chamber was then analyzed by proton transfer reactionmass spectrometry (PTR-MS; Ionicon Analytik, Innsbruck, Austria) to calculate monoterpene emission rates. Every 15 minutes, the output air flowing from the leaf chamber was also sampled for 10 additional minutes using stainless steel tubes filled with VOC adsorbents. Thereafter, the adsorbed terpenes were analyzed by thermal desorption and gas chromatography-mass spectrometry (GC-MS) to characterize the relative concentration of each single terpene. The floral terpene emissions were calculated from the difference between the concentration of terpenes from chambers clamped to flowers and the concentration from chambers with no flowers and adjusted with the flow rates. A Teflon tube connected the chamber to the PTR-MS system (50 cm long and $2 \mathrm{~mm}$ internal diameter). The system used was identical for all measurements. The flowers measured in each sample-replicate were collected each 


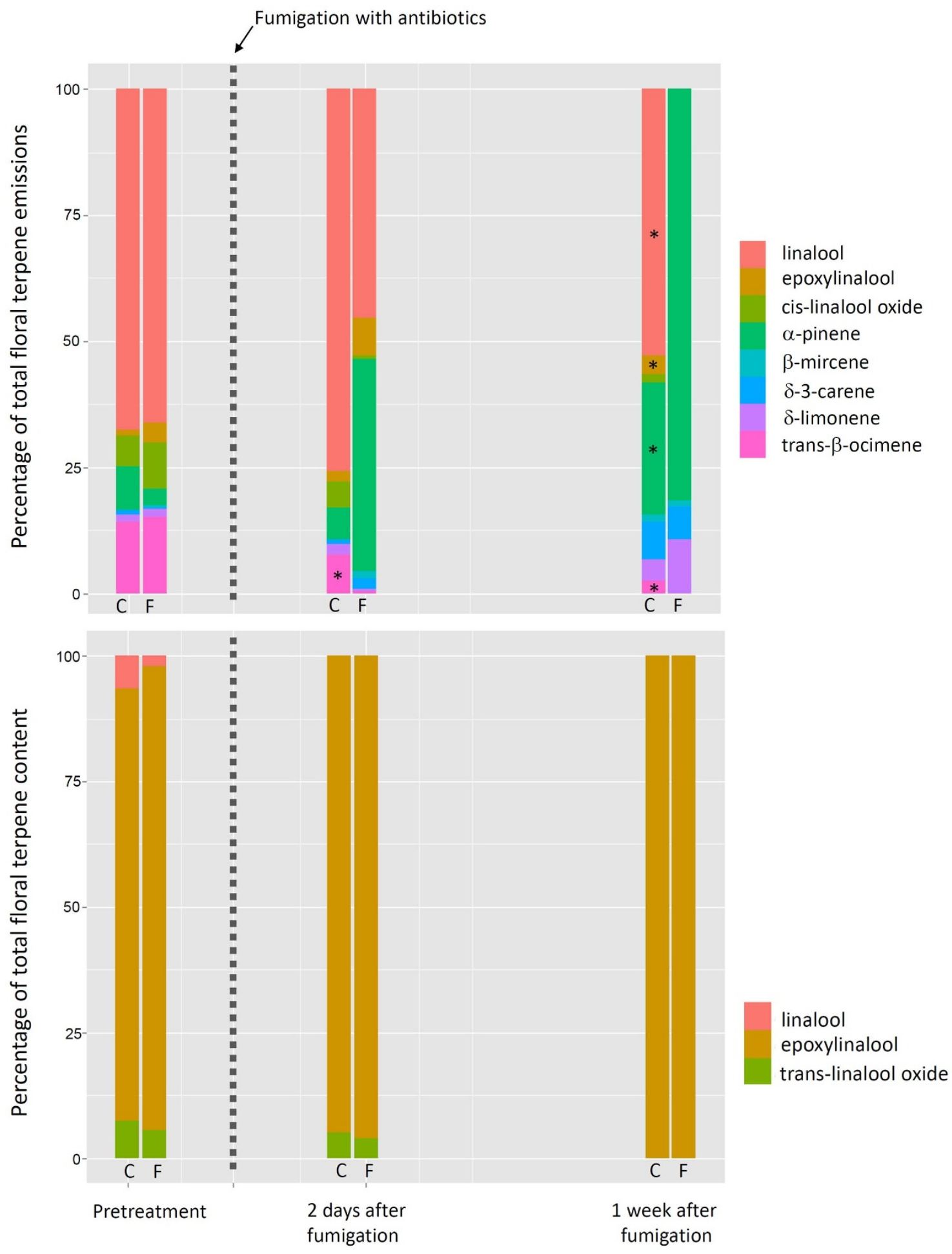

Figure $2 \mid$ Effects of antibiotic fumigation on the composition and contents of floral terpene emissions. Time course of terpene composition of floral terpene scents (a) and floral terpene contents (b) of control and antibiotic-fumigated Sambucus nigra plants. The antibiotics were applied to treated plants on day $0 .{ }^{*}$ indicates a significant difference $(P<0.05)$ between control and antibiotic-fumigated flowers (ANOVA).

sampling day, after finishing the measurements, and dried into an oven at $70^{\circ} \mathrm{C}$ until constant weight to get the dry weight of the floral emitting sample.

PTR-MS. PTR-MS is based on chemical ionization, specifically non-dissociative proton transfer from $\mathrm{H}_{3} \mathrm{O}^{+}$ions to most of the common BVOCs, and has been fully described elsewhere ${ }^{26,27}$. In our experiment, the PTR-MS drift tube was operated at $2.1 \mathrm{mbar}$ and $50^{\circ} \mathrm{C}$, with an $\mathrm{E} / \mathrm{N}$ (electric field/molecule number density) of approximately $130 \mathrm{Td}$ (townsend) $\left.\left(1 \mathrm{Td}=10^{-17} \mathrm{~V} \mathrm{~cm}\right)^{2}\right)$. The primary ion signal $\left(\mathrm{H}_{3} \mathrm{O}^{+}\right)$was maintained at approximately $6 \times 10^{6}$ counts per second. The instrument was calibrated using an aromatic mixed-gas standard (TO-14A,
Restek, Bellefonte, PA, USA) and a monoterpene gas standard (Abello Linde SA, Barcelona). Masses 155, 137 and 81 were continuously monitored to calculate monoterpene emission rates.

Terpene sampling and analysis by GC-MS. Exhaust air from the chambers was pumped through a stainless steel tube $(8 \mathrm{~cm}$ long and $0.3 \mathrm{~cm}$ internal diameter $)$ (Markes International Inc. Wilmington, USA) filled manually with the VOC adsorbents (115 mg of Tenax ${ }^{\circledR}$ and $230 \mathrm{mg}$ of Unicarb ${ }^{\circledR}$, Markes International Inc. Wilmington, USA) separated by a metallic grid. Samples were collected using a QMAX air-sampling pump (Supelco Inc., Bellefonte, PE, USA). For more details, see 
Peñuelas et al ${ }^{27,28}$. The sampling time was $10 \mathrm{~min}$, and the flow varied between 100 and $200 \mathrm{~mL} \mathrm{~min}{ }^{-1}$, depending on the adsorbent. The tubes were stored at $-28^{\circ} \mathrm{C}$ until the analysis. We also prepared extracts of each floral sample for the posterior analysis of the floral volatile concentrations with GC-MS. We froze the samples in liquid nitrogen and ground them in vials with $500 \mu \mathrm{L}$ of pentane that served as a solvent for the extracted contents.

Terpene analyses were performed using a gas chromatograph (7890A, Agilent Technologies, Santa Clara, USA) with a mass spectrometric detector (5975C inert MSD with Triple-Axis Detector, Agilent Technologies). The terpenes trapped in the tubes were processed with an automatic sample processor (TD Autosampler, Series 2 Ultra, Markes International Inc. Wilmington, USA) and desorbed using an injector (Unity, Series 2, Markes International Inc. Wilmington, USA) into a $30 \mathrm{~m} \times$ $0.25 \mathrm{~mm} \times 0.25 \mu \mathrm{m}$ film capillary column (HP-5ms, Agilent Technologies INC). The chromatographic program used for the identification and quantification of the terpenes is described in detail in Peñuelas et $\mathrm{al}^{28}$. For pre-desorption and desorption, the flow was $50 \mathrm{ml} \mathrm{min}{ }^{-1}$, the split $10 \mathrm{ml} \mathrm{min}^{-1}$, and the desorption temperature $330^{\circ} \mathrm{C}$.

Data analysis. The changes in the composition of the floral terpene emissions and concentrations were analysed by PERMANOVAs with Euclidean distances. The PERMANOVA analyses were conducted with $\mathrm{R}$ software ${ }^{29}$ using the adonis function of the vegan package ${ }^{30}$. Statistica v8.0 (StatSoft) was used to perform the ANOVAs. Percentages were transformed to the arcsine of the square root previous to the ANOVA analyses comparing control and antibiotic-fumigated flowers.

1. Lundberg, D. S. et al. Defining the core Arabidopsis thaliana root microbiome. Nature 488, 86-90 (2012).

2. Bulgarelli, D. et al. Revealing structure and assembly cues for Arabidopsis rootinhabiting bacterial microbiota. Nature 488, 91-5 (2012).

3. Vorholt, J. a. Microbial life in the phyllosphere. Nat. Rev. Microbiol. 10, 828-40 (2012).

4. Bulgarelli, D., Schlaeppi, K., Spaepen, S., Ver Loren van Themaat, E. \& SchulzeLefert, P. Structure and functions of the bacterial microbiota of plants. Annu. Rev. Plant Biol. 64, 807-38 (2013).

5. Arnold, A. E. et al. Fungal endophytes limit pathogen damage in a tropical tree. Proc. Natl. Acad. Sci. 100, 15649-15654 (2003).

6. Lindow, S. E. \& Brandl, M. T. Microbiology of the Phyllosphere. Appl. Environ. Microbiol. 69, 1875-1883 (2003)

7. Rastogi, G., Coaker, G. L. \& Leveau, J. H. J. New insights into the structure and function of phyllosphere microbiota through high-throughput molecular approaches. FEMS Microbiol. Lett. 348, 1-10 (2013).

8. Peñuelas, J. \& Terradas, J. The foliar microbiome. Trends Plant Sci. in press, (2014).

9. Peñuelas, J. et al. Biogenic volatile emissions from the soil. Plant. Cell Environ. doi: 10.1111/pce.12340 (2014).

10. Farré-Armengol, G., Filella, I., Llusia, J. \& Peñuelas, J. Floral volatile organic compounds: Between attraction and deterrence of visitors under global change. Perspect. Plant Ecol. Evol. Syst. 15, 56-67 (2013).

11. Davis, T. S., Crippen, T. L., Hofstetter, R. W. \& Tomberlin, J. K. Microbial volatile emissions as insect semiochemicals. J. Chem. Ecol. 39, 840-59 (2013).

12. Schulz, S. \& Dickschat, J. S. Bacterial volatiles: the smell of small organisms. Nat. Prod. Rep. 24, 814-42 (2007).

13. Lemfack, M. C., Nickel, J., Dunkel, M., Preissner, R. \& Piechulla, B. mVOC: a database of microbial volatiles. Nucleic Acids Res. 42, D744-8 (2014).

14. Ponzoni, C. et al. Biotransformation of acyclic monoterpenoids by Debaryomyces sp., Kluyveromyces sp., and Pichia sp. strains of environmental origin. Chem. Biodivers. 5, 471-83 (2008)

15. Mirata, M. A., Wüst, M., Mosandl, A. \& Schrader, J. Fungal Biotransformation of ( \pm )-Linalool. J. Agric. Food Chem. 56, 3287-3296 (2008).

16. De Carvalho, C. C. C. R. \& da Fonseca, M. M. R. Biotransformation of terpenes. Biotechnol. Adv. 24, 134-42 (2006).

17. Raguso, R. A. \& Pichersky, E. A day in the life of a linalool molecule: Chemical communication in a plant-pollinator system. Part 1: Linalool biosynthesis in flowering plants. Plant Species Biol. 14, 95-120 (1999).
18. Sandhu, D. K. \& Waraich, M. K. Yeasts associated with pollinating bees and flower nectar. Microb. Ecol. 11, 51-58 (1985).

19. Knudsen, J. T., Tollsten, L. \& Bergström, L. G. Floral scents-a checklist of volatile compounds by head-space techniques. Phytochemsitry 33, 253-280 (1993).

20. Pfundel, E. E., Renganathan, M., Gilmore, a. M., Yamamoto, H. Y. \& Dilley, R. a. Intrathylakoid $\mathrm{pH}$ in Isolated Pea Chloroplasts as Probed by Violaxanthin Deepoxidation. Plant Physiol. 106, 1647-1658 (1994).

21. Zwielehner, J. et al. DGGE and real-time PCR analysis of lactic acid bacteria in bacterial communities of the phyllosphere of lettuce. Mol. Nutr. Food Res. 52, 614-23 (2008).

22. Müller, T. \& Seyfarth, W. Starvation and nonculturable state in plant-associated lactic acid bacteria. Microbiol. Res. 152, 39-43 (1997).

23. Steinreiber, a \& Faber, K. Microbial epoxide hydrolases for preparative biotransformations. Curr. Opin. Biotechnol. 12, 552-8 (2001).

24. Dudareva, N., Piechulla, B. \& Pichersky, E. Biogenesis of Floral Scents. Hortic. Rev. (Am. Soc. Hortic. Sci). 24, 31-54 (1999).

25. Vidaver, A. K. Uses of antimicrobials in plant agriculture. Clin. Infect. Dis. 34, S107-S110 (2002).

26. Lindinger, W., Hansel, a. \& Jordan, a. On-line monitoring of volatile organic compounds at pptv levels by means of proton-transfer-reaction mass spectrometry (PTR-MS) medical applications, food control and environmental research. Int. J. Mass Spectrom. Ion Process. 173, 191-241 (1998).

27. Peñuelas, J., Llusià, J. \& Asensio, D. Linking isoprene with plant thermotolerance, antioxidants and monoterpene emissions. Plant, Cell Environ. 28, 278-286 (2005).

28. Peñuelas, J. et al. Photochemical reflectance index as an indirect estimator of foliar isoprenoid emissions at the ecosystem level. Nat. Commun. 4, 2604 (2013).

29. R Core Team. R: A language and environment for statistical computing. R Foundation for Statistical Computing. (2013). at $<$ http://www.R-project.org/> Date of access: 21/04/2014

30. Oksanen, J. et al. vegan: Community Ecology Package. (2013). at $<$ http://cran.rproject.org $/$ package $=$ vegan $>$ Date of access: 21/04/2014

\section{Acknowledgments}

This research was supported by the Spanish Government grant CGL2013-48074-P, the Catalan Government project SGR 2014-274 and the European Research Council Synergy grant ERC-SyG-610028 IMBALANCE-P.

\section{Author contributions}

J.P., J.T., G.F.A. and I.F. designed the research with the help of the other co-authors, L.R., A.G. and J.S. J.P., G.F.A., J.L.L. and I.F. conducted the experiments. All authors participated in the analyses, but G.F.A. and J.L.L. conducted most of the GC analyses, and I.F. and J.P. conducted most of the PTR-MS analyses. J.P. wrote the first draft of the manuscript and thereafter all authors contributed to the writing and the drafting of the figures.

\section{Additional information}

Competing financial interests: The authors declare no competing financial interests.

How to cite this article: Peñuelas, J. et al. Removal of floral microbiota reduces floral terpene emissions. Sci. Rep. 4, 6727; DOI:10.1038/srep06727 (2014).

This work is licensed under a Creative Commons Attribution-NonCommercialNoDerivs 4.0 International License. The images or other third party material in this article are included in the article's Creative Commons license, unless indicated otherwise in the credit line; if the material is not included under the Creative Commons license, users will need to obtain permission from the license holder in order to reproduce the material. To view a copy of this license, visit http:// creativecommons.org/licenses/by-nc-nd/4.0/ 